Motrivivência $\quad$ v. $27, \quad$ n. $44, \quad$ p. $64-78$, maio/2015

\title{
O PAPEL DA MÍDIA SERGIPANA NAS ESTRATÉGIAS DE AGENDAMENTO NA MOBILIZAÇÃO DA DIALÉTICA GLOBAL-LOCAL A PARTIR DE UMA SITUAÇÃO CONCRETA: as Olimpíadas/2012
}

\author{
Cristiono Mezzaroba' \\ Sérgio Dorenski Dantas Ribeiro² \\ Paula Aragão ${ }^{3}$ \\ André Marsiglia Quaranta ${ }^{4}$ \\ Luciana Carolline Pina Garcia ${ }^{5}$ \\ Silvan Menezes Dos Santos ${ }^{6}$
}

\section{RESUMO}

Com os megaeventos esportivos acontecendo no Brasil (Jogos Pan-americanos 2007; Copa das Confederações 2013; Copa do Mundo 2014 e Olimpíadas/Paraolimpíadas 2016), visualizamos um período profícuo e instigador para pesquisas em torno deste objeto, concentrando nosso olhar para as Olimpíadas de Londres/2012. A exaltação do fenômeno esportivo trouxe, nesta pesquisa, as diversas faces que a mídia pode apresentar-se e associar-se (no tocante à economia, cultura, política, educação etc.).

1 Doutorando em Educação. Docente da UFS. Florianópolis / Santa Catarina, Brasil.

E-mail: cristiano_mezzaroba@yahoo.com.br

2 Doutor em Educação. Docente da UFS. Aracaju / Sergipe, Brasil.

E-mail: dorenski@gmail.com

3 Mestre em Educação Física. Docente da rede Municipal de Educação - Graccho Cardoso/SE. Sergipe, Brasil.

E-mail: aragao_paula@hotmail.com

4 Mestre em Educação Física. Docente da rede de Educação de Sergipe. Sergipe, Brasil.

E-mail: andrequaranta@gmail.com

5 Mestranda em Educação. Aracaju / Sergipe, Brasil.

E-mail: luciana.carolpina@gmail.com

6 Doutorando em Educação Física. Curitiba / Paraná, Brasil.

E-mail: bammenezes90@gmail.com 
Nosso objetivo foi analisar como a mídia no estado de Sergipe antecipou e deu visibilidade às Olimpíadas/2012, construindo um "agendamento midiático-esportivo", a partir da estratégia da mobilização da dialética global-local. De cunho qualitativo e de caráter descritivo-exploratório, a pesquisa desenvolveu-se em três eixos: mídia impressa, digital e televisiva - que permitiram evidenciar a baixa efetivação da estratégia de agendamento e da dialética global-local, seja em virtude do amadorismo das entidades jornalísticas, seja, principalmente, pela ausência de interesse, pois, não havia atletas sergipanos na competição.

Palavras-chave: Agendamento midiático-esportivo; Olimpíadas2012; Mídia esportiva

\section{CONSIDERAÇÕES INICIAIS}

O Brasil está passando pela denominada "década dos megaeventos esportivos" iniciada com os Jogos Pan-americanos Rio/2007 e com fim previsto para as Olimpíadas e Paraolimpíadas de 2016 - ambas na cidade do Rio de Janeiro. Vivenciamos e vivenciaremos um momento épico no tocante à exacerbação do fenômeno esportivo, porém, contraditoriamente, estamos submersos a legados de corrupção; falta de organização e planejamento na estruturação dos jogos; descaso e frieza para com outras demandas sociais, políticas e econômicas que assolam a sociedade brasileira.

Neste intervalo de tempo "esportivo", ou seja, de 2007 a 2016, que conclama os maiores signos no tocante à midiatização do fenômeno esportivo, passamos também pelo momento sublime da contemplação do esporte no Brasil, que foi a Copa do Mundo de Futebol/2014, pela segunda vez em território brasileiro. Esta modalidade esportiva carrega em si um rastro luminoso que envolve a cultura, a economia, a política, o fanatismo, o nacionalismo, alegria, tristeza, raiva, sentimentos diversos que se somam aos megaeventos esportivos.

$\mathrm{Na}$ pesquisa que realizamos, nosso olhar centrou-se nos Jogos Olímpicos de
Londres/2012 (JO/2012), na Inglaterra, tendo em vista que pairou pelos holofotes da mídia a ideia de "preparação brasileira" para o evento que ocorrerá no Brasil quatro anos depois e, com isso, a alegação de que era crucial que o país aprendesse a lidar, principalmente, com as questões de infraestrutura.

O que esteve em pauta nesta investigação foi a observação de como a mídia pode criar, no imaginário coletivo, a sensação de pertencimento à cultura brasileira mesmo afastada geograficamente no tempo e espaço. Nosso entendimento é que o fenômeno esportivo - principalmente em época de megaeventos - é o ingrediente ideal para esta aproximação e assim, a mídia em suas diversas formas de veiculação, como televisão, jornais impressos e internet, cumpre esta proeza de deixar muito semelhantes e, também, muito pertos, sentimentos, cultura, economia, entre outros elementos que compõem a vida em sociedade.

Temos a clareza que a mídia, na cobertura de determinados eventos, cria um campo próprio e peculiar para mediar informações que garantem um retorno do ponto de vista das atenções do público. Junto a isso, também promove a criação de produtos culturais simbólicos em torno 
dos acontecimentos esportivos que implica em compreensões e representações deste universo esportivo, como também dos interesses mercadológicos. Por isso, o processo de espetacularização do esporte ganha uma dimensão mercantil (tomado como mercadoria) e espetacular em que esta espetacularização passa pelo refino dos recursos audiovisuais, virtuais, simbólicos, entre outros, para garantir o encontro perfeito entre sua oferta e seu consumo. Foi nesse aspecto que pretendemos contribuir com tal discussão, tratando em especial do contexto do estado de Sergipe (SE), um estado "periférico" nas questões esportivas nacionais e por não ser sede de nenhum outro megaevento, mas que, pelas possibilidades midiáticas e de sua dimensão onipresente, recebe os efeitos deste domínio.

Estamos lidando com uma espécie de poder - do esporte em parceria com a mídia, uma relação de "mão dupla" - que invade nossos lares, que agrega outros sentidos e significados às práticas corporais da sociedade e que tem implicações diretas nos conteúdos da Educação Física (EF) escolar. Por isso, diante de um evento esportivo desta magnitude, como são as Olimpíadas, é que observamos mais facilmente as estratégias de visibilidade desses megaeventos que caracterizam o chamado "agendamento midiático-esportivo" (MEZZAROBA; MESSA; PIRES; 2011).

Nesta Odisséia que representou uma aventura no campo da mídia, mesclamos o conhecimento midiático a partir de diversos aportes como: agenda-setting (WOLF, 2001) e da sua derivação agendamento midiático-esportivo; a dialética global-local (BITENCOURT, 2004); a falação esportiva (ECO, 1984; BETTI, 2001); e a circularidade circular da informação (BOURDIEU, 1997), entre outros, no intuito de apreender o objeto em suas diversas faces.

Vale ressaltar que o presente texto está constituído numa síntese de uma pesquisa coletiva maior, do Grupo LaboMídia/ UFS que foi desenvolvida sob o viés de quatro eixos temáticos/subprojetos ${ }^{7}$ realizados na apreensão do objeto e que, portanto, traz algumas estratégias de captura que se diferenciam entre si, mas que contemplam a relação da dialética global-local e do agendamento esportivo.

Estes eixos temáticos, do ponto de vista metodológico, caracterizam-se como observacional descritivo, de natureza qualitativa, sendo que o processo de organização, descrição e discussão dos dados esteve orientado pelo método da análise de conteúdo (BARDIN, 2009). No tocante ao eixo sobre mídia televisiva operamos na captura e análise a partir da hermenêutica de profundidade (VERONESE; GUARESCHI, 2006).

A partir do olhar sobre a mídia sergipana em torno dos JO/2012, organizamos nosso texto em três momentos: num primeiro momento apresentamos uma síntese da pesquisa sobre a mídia impressa sergipana, especificamente um jornal; na segunda

7 Este texto é um recorte da pesquisa “As Olimpíadas e as Paraolimpíadas de 2012 na mídia sergipana: Investigando as estratégias de agendamento e a mobilização da dialética global-local”, publicado pela Editora da UFS, em 2014. Aqui, trouxemos uma síntese dos três eixos que nortearam a investigação, sendo que o quarto eixo, que foi um estudo de recepção com professores de Educação Física do Estado de Sergipe, foi retirado desse recorte, ficando, portanto, apenas a análise dos veículos midiáticos daquele estado brasileiro. 
parte do escrito suspendemos as análises da mídia digital (dois portais de informação na internet); na sessão posterior dissertamos sobre a mídia televisiva, em que pesquisamos um programa jornalístico. Por fim, nossas considerações finais, em que são expostas algumas lacunas e sugestões da pesquisa.

\section{Um olhar sobre a Mídia Sergipana em torno dos Jo/2012}

O desenvolvimento das Tecnologias de Informação e Comunicação (TIC's) possibilitou um encurtamento na relação espaço e tempo. Diminuímos a distância em um simples toque ou clic e, por conta disso, o discurso midiático nos aproxima e também nos distancia dos diversos fatos e acontecimentos que ocorrem em escala global. Neste sentido, nesta etapa da pesquisa analisamos a mídia impressa sergipana em sua narrativa das diversas informações que perfazem os JO/2012. Estabelecemos um recorte temporal compreendido entre os dias 10/05 a 27/07/2012 (dia que antecedeu o início dos JO), o que nos garantiu um corpus para análise constituído por um conjunto de edições diárias do Jornal da Cidade $(J C)^{8}$, em que observamos a cobertura e as estratégias utilizadas para aproximar este evento esportivo ao pequeno estado de Sergipe. Neste aspecto, o processo de captura dos dados revelou três momentos de destaque em que o tema $\mathrm{JO} / 2012$ esteve em pauta.

$\mathrm{O}$ primeiro momento refere-se ao Campeonato Brasileiro de Boxe que esteve em evidência na mídia sergipana, pois, o referido estado foi sede da competição no período de 10 a 17 de junho de 2012, em Aracaju.

A relação com o momento olímpico foi estabelecida com a participação dos atletas que compuseram a seleção olímpica de boxe. Com isso, as edições dos dias 30/05; $10,11,13$ e 14/06/2012 trouxeram informações sobre o evento, numa perspectiva de agendamento para o público, e, também, a participação desses atletas. Fica evidente que o evento - apesar de nacional, mas realizado em Sergipe - esboçou além da importância da competição para o contexto sergipano, a sua relação com o evento olímpico (global), pois, ele antecedeu um evento de caráter global de grande importância. Este foi um aspecto importante e que foi materializado na fala do presidente da Federação Sergipana de Boxe, Valter Duarte, em que expunha que a seleção olímpica de boxe seguiria praticamente de Sergipe para Londres.

BRASILEIRO DE BOXE - [...] Esta será a quarta vez consecutiva que Sergipe promove um Brasileiro de Boxe [...]. Aqui, será anunciada a formação da Equipe Olímpica que representará o Brasil nos Jogos Olímpicos de Londres no mês de julho. A Seleção Brasileira Olímpica de Boxe, praticamente seguirá de Sergipe para Londres [...]. (JORNAL DA CIDADE, p. B-9 de 30/05/2012).

BRASILEIRO DE BOXE-CAMPEONATO EM ARACAJU TERÁ ATLETAS OLÍMPICOS - [...] trata-se de uma das maiores competições de boxe [...] reveste uma

8 O Jornal da Cidade constitui-se em um dos mais antigos e tradicionais diário jornalístico da mídia impressa sergipana que desde a década de 1970 cumpre o papel de mediar as informações nos âmbitos local, nacional e internacional. 
característica especial, pois contará com a participação de atletas que integram a delegação brasileira, nos Jogos Olímpicos de Londres [...]. (JORNAL DA CIDADE, p. B-9 de 11/06/2012).

Com isto a presença de um evento desta natureza e com atletas que faziam parte da seleção olímpica, estabeleceu laços de aproximação entre o global e o local. Tal constatação é observável na tentativa de projetar os atletas sergipanos para o próximo ciclo olímpico, ou seja, a pretensão da formação de uma equipe para os JO/2016. Isto é reiterado com o aumento de praticantes dessa modalidade no estado.

Observamos que a presença dos atletas olímpicos do boxe trouxe para o estado um significado maior nas ações sociais que são realizadas tendo o esporte como meio, o qual foi materializado a partir do encontro desses atletas com a Escola de Esportes Professor Kardec ${ }^{9}$, que tem como lema a inclusão social através do esporte. Nos fragmentos que seguem, ilustramos como isso pode ser percebido conforme as matérias referentes aos dias 13 e 14/06/2012 em que os atletas olímpicos visitam a ação social realizada por esta instituição:

OLHAR OLÍMPICO - ATLETAS VISITAM ESCOLA DE ESPORTES - Os sete atletas da Seleção brasileira de Boxe, que representarão o Brasil nos Jogos Olímpicos de Londres [...] visitarão a Escola de Esportes Professor Kardec, no Bairro Santa Maria [...]. (JORNAL DA CIDADE, p. B-9 de 13/06/2012).
ESCOLA DE ESPORTES/OLÍMPICOS ELOGIAM - [...] Projetos desse tipo, [...] deveriam ser homologados pelo Ministério dos Esportes e se tornar obrigatórios, como política de esporte em todos os estados [...]. (JORNAL DA CIDADE, p. B-9 de 14/06/2012).

O segundo momento que percebemos a alusão aos JO/2012 e, com isso, estabelecendo uma relação global-local (Olimpíadas e cultura sergipana), foi em relação ao artista sergipano, natural da cidade de Japaratuba/SE, Arthur Bispo do Rosário. Apesar de ser um contexto artístico e, portanto, fora do âmbito esportivo, a referência deu-se pelo fato de suas obras serem expostas no Victoria \& Albert $^{10} \mathrm{em}$ Londres. Foram mais de oitenta peças do artista sergipano que fizeram parte da exposição intitulada "Azul dos Ventos" e estava inserida no projeto cultural dos JO/2012.

BISPO DO ROSÁRIO- Obras De Arthur Bispo exposta em Londres - As obras de arte do sergipano Arthur Bispo do Rosário continua ganhando o mundo. No período de 13 de agosto a 28 de outubro elas estarão expostas em Londres, no renomado museu Victoria \& Albert [...] faz parte do projeto cultural dos Jogos Olímpicos de Londres de 2012 (JORNAL DA CIDADE, s/p de 14/07/2012).

O terceiro momento refere-se à publicidade e propaganda relacionando às questões de espaços de lazer para as crianças com tema dos JO/2012. Neste aspecto,

9 Esta escola fica localizada no Bairro Santa Maria, antigo Lamarão, na periferia de Aracaju e desenvolve Projetos Sociais com apoio da Secretaria de Estado do Esporte e Lazer como "Vida Alegre e Sergipe mais Justo".

10 O Victoria \& Albert é um dos mais importantes museus de arte e design do mundo. Fundado em 1852, ele recebeu o nome em homenagem à rainha Vitória e ao príncipe Albert. Fonte: Jornal da Cidade de 14/07/2012. 
apresenta um merchandising que envolve o contexto sergipano e espaços inspirados nos JO. É determinante o uso da mídia através de um caderno do Jornal, a Coluna de Thaís Bezerra - para fins específicos na relação com o capital, ou seja, a propaganda como mercadoria. Com isso, as informações esboçaram como uma construtora fez o lançamento de um dos seus empreendimentos com o nome de "Jardins de Londres", aproveitando assim o momento dos JO.

LONDON, LONDON - [...] Londres irá abrigar as próximas Olimpíadas. Atenta a tudo isto, a Norcon Rossi inova e traz a cultura inglesa para a campanha de pré-lançamento do Jardins de Londres, em Aracaju. A empresa instalou a mesma cabine telefônica, idênticas às tradições londrinas com soldados fardados iguais aos da guarda real [...]. (JORNAL DA CIDADE, s/p - COLUNA THAIS BEZERRA - 11/06/2012).

Em outro momento - referente à matéria do dia 30/06/2012 - observamos mais uma vez a relação "propaganda e mercadoria" tendo como pano de fundo os JO/2012, em que os shoppings da capital sergipana disponibilizaram dispositivos e espaços de lazer para as crianças inspirados nos JO.

JULHO SEM AULAS/Colônias de férias atraem crianças - [...] A partir do dia $1^{\circ}$ de julho, na praça de eventos de um dos shoppings da capital será montada uma arena olímpica, com diversos dispositivos de lazer inspirados nas Olimpíadas de Londres. Na arena, crianças de dois a 12 anos se divertirão com labirinto, cama elástica, eurobungy e spider. (JORNAL DA CIDADE, 30/06/2012).

Encontramos ainda, alguns anúncios publicitários que ocuparam uma página inteira do jornal impresso, o que marca a publicidade em relação direta com a mídia e o esporte, tendo como tema os JO/2012. Aliado a isto, fica nítida a interconexão entre os meios, ou seja, a mídia impressa e a televisiva em "comunhão de bens" para o agendamento publicitário e esportivo. Fato este observado na veiculação de sua agenda diária e programação da TV Atalaia, a emissora oficial sergipana, afiliada à Rede Record, que transmitiu os JO/2012, já se referindo ao evento e aproveitando também para isto, as competições do futebol que começara antes da abertura oficial do JO.

JOGOS OLÍMPICOS DE LONDRES 2012, SÓ NA RECORD. [...] 25/07 Futebol Feminino - Brasil x Camarões às $02 \mathrm{~h} 30 \mathrm{da}$ tarde; 26/07 - Futebol Masculino - Brasil x Egito às $03 \mathrm{~h} 30$ da tarde. (JORNAL DA CIDADE, s/p de 23/07/2012).

Neste sentido, observamos e analisamos os dados numa perspectiva qualitativa em que focou, especificamente, em questões que trazem as relações do poder simbólico/econômico (THOMPSON, 1998) a partir do discurso de um veículo midiático - mídia impressa sergipana - em que o agendamento na dialética global-local esteve em pauta.

Assim, percebemos como a mídia impressa, especificamente o Jornal pesquisado, manteve uma aproximação com o fenômeno esportivo, os JO/2012, e repassou para a sociedade informações no tocante ao universo esportivo relacionado àquele megaevento esportivo, mas, principalmente, as suas tramas com a publicidade. Este aspecto foi determinante para as estratégias que o JC utilizou para trazer informações sobre os JO/2012. Seja no Campeonato Brasileiro de Boxe, seja na apresentação de um artista 
sergipano ao público leitor, ou mesmo nas estratégias publicitárias, a dimensão do âmbito local em relação ao evento de caráter global estiveram presentes.

Por fim, ressaltamos que a diferença crucial entre os JO/2012 e outras competições esportivas já realizadas - caso dos Jogos Pan-Americanos de 2007 e os JO de Pequim/2008 - e que foram basilares para aproximação do público ao evento e com isso, criar um sentimento de pertencimento (RIBEIRO et al, 2009; QUARANTA; MESSA, 2009), estavam pautadas na presença de atletas sergipanos que participaram destes eventos. No entanto, este atrativo não aconteceu neste último megaevento, o que foi preciso criar outras estratégias para relacionar um evento (global) ao aspecto cultural local.

\section{A cobertura dos JO de Londres/2012 na visão dos portais ${ }^{11}$ digitais sergipanos}

Neste eixo temático da pesquisa, ainda na perspectiva de analisar e compreender as estratégias de agendamento e da dialética global-local, bem como as interfaces da mídia com o evento esportivo, sua espetacularização e comercialização a partir da cobertura dos JO/2012, demos ênfase aos sítios virtuais sergipanos que incidem diretamente neste público.

Analisamos dois portais de jornalismo digital sergipano, o Portal Infonet e o Emsergipe.com, atualizado para G1.com/ $S E$, que é o portal da TV Sergipe - afiliada oficial da Rede Globo. Esta estratégia metodológica foi um diferencial na pesquisa, que, em certa medida, trouxe uma excepcionalidade, pois, observamos a carência de pesquisas neste tema e utilizando da rede de comunicação mundial - internet - na análise de conteúdos dos portais informativos.

Este estudo caracterizou-se como descritivo-exploratório em que foram sistematizadas observações diárias durante os meses de abril a julho (até dia 27) do ano de 2012 nos três turnos: manhã, tarde e noite, em que foram capturadas reportagens e informações que mencionaram ou fizeram alusão há algum fato ou pessoa relacionados aos JO/2012. Após esta etapa, os achados foram arquivados em um banco de dados por ordem cronológica de veiculação. Com isso, contabilizamos após 117 dias de acesso, um montante de 23 matérias (Infonet e G1.com/SE - 9 e 14 matérias, respectivamente) que foram basilares para a nossa análise de conteúdo (BARDIN, 2009).

Numa primeira análise, observamos que a perspectiva da dialética global-local esteve mais em pauta, pois, no total de 23, catalogamos 17 que fazem menção ao estado de SE e à Londres/2012. Com isso, a categoria de agendamento, nos dois portais observados, foi menos incisiva. No entanto, ela se apresenta numa perspectiva de projetar futuros atletas sergipanos para o contexto olímpico, principalmente, para as Olimpíadas/2016, uma vez que o estado de Sergipe não dispunha de atletas em Londres/2012.

11 São dois Portais Infonet e Emsergipe.com que trazem como slogans, respectivamente: "sua internet com muito mais vantagens"; "tudo sobre notícias, esporte e entretenimento". 
Promessa - O presidente da Federação Sergipana de Boxe, Walter Duarte, disse que 21 atletas sergipanos estão disputando boas colocações no pódio, e fala sobre um atleta em particular. “O pugilista Carlos Rafael tem apenas 15 anos e já foi pré-convocado para a seleção brasileira. Esse atleta é uma esperança para as olimpíadas de 2016, e não só ele, como outros pugilistas nos ajudam a mostrar a cara de Sergipe para o Brasil", finalizou. Por: Monique Garcez e Raquel Almeida (www.infonet.com. br em 11/06/2012).

Ainda, neste aspecto da projeção de atletas sergipanos e que implica também em certo agendamento enquanto "promessas" para o esporte, destacamos as matérias das lutadoras de Taekwondo ${ }^{12}$ que trazem a marca da veiculação midiática pela conquista do terceiro lugar numa competição de caráter nacional; do pugilista Leonardo Celestino $^{13}$ que fora convocado para a Seleção Brasileira de Boxe e que, portanto, garante uma projeção futura. Ambos os recortes da mídia digital fazem alusão a uma perspectiva olímpica, mas, encontramos também, a modalidade Karatê e, por não ser ainda um esporte olímpico, esta projeção é para aspectos nacionais e internacionais dos sergipanos ${ }^{14}$.

Sergipanas conquistam o bronze no Brasileiro Juvenil de Taekwondo/Nayanne Caldeira e Iris Larisse disputaram o torneio nacional em Goiânia (grifo nosso) - No último final de semana, dias 7 e 8 de julho, duas sergipanas representaram bem o Estado no Campeonato Brasileiro Juvenil de Taekwondo. Nayanne Caldeira e Iris Larisse conquistaram a medalha de bronze em suas respectivas categorias. [...]. Foi o primeiro torneio nacional da lutadora Nayanne Caldeira, de 17 anos, que possui dois meses de faixa preta na modalidade. Ela competiu na categoria até $55 \mathrm{~kg}$ - Foi uma grande conquista. Sei que o ouro seria bem melhor, mas o bronze valeu a pena. O que importa é não desistir nunca do seu sonho. Eu ainda quero chegar a competir fora do país e representar o Brasil nas olimpíadas - afirmou Nayanne. Por: Felipe Martins. (globoesporte.globo.com em 11/07/2012).

Sergipano Leonardo Celestino é convocado para Seleção Brasileira/João Carlos Barros gostou da atuação do pugilista diante de Everton Lopes (grifo nosso) - O sergipano Leonardo Celestino estreou na categoria adulto no campeonato brasileiro diante do atual campeão mundial, Everton Lopes, com derrota, mas o pugilista de 16 anos agradou a comissão técnica da seleção brasileira e foi convocado logo após a luta. Resistir aos fortes golpes de Everton Lopes por dois round e certa técnica dentro do ringue chamaram atenção de João Carlos Barros, treinador responsável pelo time olímpico que vai disputar os jogos de Londres. (globoesporte.globo.com em 12/06/2012)

Estamos convictos de que os portais de informação e sites de notícias na internet podem ser peças-chaves na conformação e ampliação de uma cultura esportiva local, sem deixar que a dinâmica imediatista (BASTOS, 2012) afete os pilares

12 Disponível em: http://globoesporte.globo.com/se/noticia/2012/07/sergipanas-conquistam-o-bronze-no-brasileirojuvenil-de-taekwondo.html. Acesso: 25/02/2013.

13 Disponível em: http://globoesporte.globo.com/se/noticia/2012/06/sergipano-leonardo-celestino-e-convocado-para-selecao-brasileira.html. Acesso: 12/06/2012.

14 Vide informação em: http://www.infonet.com.br/esporte/ler.asp?id=131158\&titulo=noticias. Acesso: 13/07/2012. 
do jornalismo no seu compromisso social (KUCINSKI, 2012), pois, constituem-se a perspectiva presente e futura de linguagem e comunicação entre as pessoas. Por isso, consideramos que, apesar do número reduzido de matérias encontradas, os portais destacaram modalidades esportivas que possuem ínfima projeção nacional, ou que ainda estão ganhando espaço no cenário no qual persiste a monocultura futebolística.

Outro aspecto que nos chamou a atenção está relacionado ao convite à técnica sergipana de ginástica rítmica, Cristina Vidal - que expressa ineditismo e reconhecimento - a participar como árbitra das competições nos JO/2012 ${ }^{15}$, é o exemplo mais nítido da utilização da dialética global-local para o público sergipano. Talvez, este tenha sido o maior acontecimento na representação global-local que envolveu os JO e a realidade sergipana.

Sergipana é convocada para arbitrar nas Olimpíadas/Cristina Vital será a única árbitra brasileira em Londres (grifo nosso) - A sergipana Maria Cristina Vital foi a única árbitra brasileira de Ginástica Rítmica, convocada pela Federação Internacional de Ginástica (FIG), para arbitrar nas Olimpíadas de Londres. [...]. Árbitra internacional desde 1987, Maria Cristina Vital ficou surpresa com a convocação. "Eu nem sonhava que um dia pudesse arbitrar as Olimpíadas. Estou muito feliz. É a coroação da carreira de qualquer árbitro. Com essa convocação inédita, confirmamos que a Ginástica Rítmica do Brasil ganhou o respeito da FIG e mostramos aos árbitros nacionais, que é possível chegar longe", comemora
Cristina Vital (www.infonet.com.br em 11/04/2012).

Percebemos, assim, como a mídia de modo geral, e os dois portais de modo particular, reproduzem a lógica da circularidade circular da informação (BOURDIEU, 1997), pois trazem semelhanças e reproduzem um fato, uma informação de modo semelhante, como ficou caracterizado nas notícias sobre o Campeonato Brasileiro de Boxe Olímpico, bem como, a ênfase na presença dos boxeadores que circularam pelo estado e que tinham como destino os JO.

As notícias têm suas particularidade e finalidades, mas, decididamente, o caráter de mercadoria é dominante, ou seja, aquilo que pode gerar mais acesso e, consequentemente, ser mais apreciado por uma pluralidade de potenciais consumidores (THOMPSON, 1998) tem mais destaque no meio midiático. Como explica Jorge (2008), o corolário da notícia é dado pelo ato de consumir e pela razão de identificar-se com algo. Assim, vemos a informação transformada em mercadoria com apelos estéticos, emocionais e sensacionais (ZUIN, 2001).

Desse modo, observamos também o destaque para a Copa Brasil de Tênis de Mesa, cuja cobertura trouxe como destaque o fetiche provocado pelo mesatenista Hugo Hoyama $^{16}$. Sua história de conquistas no âmbito nacional e internacional, e, portanto, seu reconhecimento do público em geral que fora garantido na ênfase na falação esportiva e do esporte espetáculo (BETTI,

15 Disponível em: http://www.infonet.com.br/esporte/ler.asp?id=126764\&pagina Acesso: 12/04/2012.

16 Disponível em: http://globoesporte.globo.com/se/noticia/2012/04/hugo-hoyama-conquista-medalha-de-ouro-na-copa-brasil-em-aracaju.html. Acesso: 13/04/2012. 
1998) e na construção do ídolo (e agora, com sua participação nos JO/2012), garantiu o destaque nas páginas eletrônicas:

\begin{abstract}
Hugo Hoyama conquista medalha de ouro na Copa Brasil em Aracaju/mesatenista precisou vencer apenas dois duelos para conquistar o título (grifo nosso) - [...]. é sempre importante levar o título para casa principalmente antes das Olímpiadas de Londres para sempre ter uma motivação a mais. Fiquei muito feliz em ver que o pessoal daqui gostou e a garotada está se interessando pelo esporte - afirmou Hugo. Por Felipe Martins (globoesporte.globo. com em 13/04/2012).
\end{abstract}

Assim, entendemos que os portais analisados ainda apresentam uma linha amadora no tocante à relação esporte e mídia. Talvez por conta da própria falta de exigência que nós, enquanto sujeitos receptores das mensagens, não tenhamos uma cultura mais ampla de aproximação com este meio de comunicação, o que implica um imobilismo no seu próprio formato de produção e veiculação, um tanto tradicional.

\section{Um telejornal sergipano em observação sobre os JO/2012: Jornal do Estado}

Temos clareza do impacto que a televisão carrega em si devido a sua presença na vida das pessoas. Um poder - simbólico (THOMPSON, 1998) - que paira sobre quase todos os lares no território brasileiro. Compreendemos e percebemos a ascensão da internet e com ela, os equipamentos computacionais que fazem emergir todas as mídias, portanto, sua presença junto às pessoas é cada vez maior, mas, ainda, a televisão consegue "devorar" as outras mídias (BETTI, 2001).

Isto posto, observamos a mídia televisiva sergipana, em específico, escolhemos o programa jornalístico Jornal do Estado $(\mathrm{JE})^{17}$, um dos jornais mais importantes do contexto midiático de SE da TV Atalaia, afiliada da Rede Record, emissora detentora dos direitos de transmissão dos JO/2012 ${ }^{18}$.

Nossa observação diária para coleta de dados foi construída a partir do discurso midiático do referido telejornal, sendo que o início da observação ocorreu em 18/06/2012 com término dia 21/08/2012, após a cerimônia de encerramento do evento. Elaboramos a análise a partir da Hermenêutica de Profundidade (HP) de acordo com Veronese e Guareschi (2006).

Tratando especificamente do período correspondente ao agendamento dos JO/2012 até sua temporada de realização, nossa análise formal das observações diárias do JE nos levou a perceber quatro categorias de atitudes, São elas:

1. Manutenção da programação jornalística diária;

2. Ruptura com o princípio regionalista de sua programação para dar

17 Exibido em 2 edições: às $12 \mathrm{~h}$ de segunda à sexta e às 19h30min de segunda à sábado, ambas com 30 minutos. A $1^{\text {a }}$ Edição com pauta diversificada; notícias factuais, cultural, registro ao vivo dos acontecimentos e os fatos esportivos que tem nessa edição uma exibição especial chamada de "Esporte Agora; A 2a Edição se caracteriza pela continuidade das notícias da $1^{\text {a }}$ Edição somada aos fatos ocorridos no período vespertino. É voltada para a cobertura política, policial, turismo com pouca ou nenhuma ênfase para o esporte. Maiores informações no site: http://www.atalaiaagora.com.br.

18 Fundada pelo ex-governador Augusto Franco em 1975, a TV Atalaia atualmente é administrada pelo empresário Walter Franco. Opera no Canal 8 VHF e é afiliada da Rede Record de Televisão. 
espaço à retransmissão de reportagens produzidas pela emissora matriz referentes aos $\mathrm{JO}$ durante $\mathrm{O}$ período de sua realização;

3. Anúncios de agendamento dos JO nos intervalos do telejornal vinculados a interesses publicitários;

4. Ausência de referências e produções jornalísticas locais em relação ao tema dos JO, tais como o ponto de vista ou expectativa do cidadão sergipano e seus setores de lazer e de trabalho acerca do megaevento.

Sem enfatizar a produção de matéria e reportagem jornalística sobre a perspectiva dos cidadãos sergipanos sobre o megaevento, víamos as chamadas no "momento do esporte" - uma espécie de atrativo sobre os JO/2012 - que se limitou apenas em descrever os resultados das competições com base em fontes externas. Não foi apresentado qualquer tipo de análise técnica, política, econômica ou cultural sobre os JO e o contexto local. Todas as outras matérias e reportagens transmitidas pelo mesmo telejornal foram produzidas pela emissora nacional, tratando do contexto específico do megaevento, em relação às quais o JE se posicionou como mero retransmissor. Uma resposta possível para essa estruturação básica da cobertura jornalística por parte do JE em relação aos JO/2012 pode ser encontrada na dialética global-local estabelecida entre a emissora afiliada, TV Atalaia, e a sua matriz, Rede Record de Televisão.

Nossa hipótese consiste em dizer que o JE não planejou e programou uma produção jornalística local devido ao fato de ter se submetido aos desígnios de sua fonte empresarial (BOURDIEU, 1997). Isto fica evidente pelo fato de o referido telejornal ter ferido seu princípio fundamental de tratar das questões e expectativas locais que possam ser motivadas por acontecimentos e fenômenos de várias ordens e origens. Enfim, o modo como se configurou a dialética entre o local e o nacional demonstra que as afiliadas não são parceiras horizontais de suas matrizes ou geradoras. Sem embargo, existem algumas relações de poder que prezam pela submissão das afiliadas em face das geradoras ou matrizes.

Percebemos, de fato, que o local deu lugar ao global na cobertura jornalística do JE acerca dos JO/2012, ou seja, na perspectiva de observação da dialética local e nacional entre TV Atalaia e sua geradora Rede Record de Televisão, a dimensão estadual/local deu lugar aos aspectos e interesses nacionais e internacionais da emissora. Ao nosso ver ficou marcada a força institucional do fenômeno esportivo na modernidade e sua dimensão massificadora que fez subsumir as características da cultura local.

A análise dos dados ratificou a hipótese de que a estrutura da cobertura dos JO/2012 consistiu na submissão do local aos interesses nacionais e internacionais próprios da emissora geradora. Vimos que os interesses hegemônicos e massificadores das emissoras de televisão se uniram aos interesses por parte do mundo esportivo mercadológico que, em detrimento das culturas locais, vêm impondo regras e atitudes padronizadas e pasteurizadas para atingirem seus interesses ideológicos e econômicos, sobrepondo-se às manifestações populares e periféricas.

Por fim, ficou claro que o resultado final alcançado pela investigação, no tocante à mídia televisiva, esboçou uma escassez ou quase ausência de fatos referentes aos 
JO/2012, uma vez que o JE optou por retransmitir as reportagens da agenda nacional sem dar ênfase às perspectivas locais acerca do megaevento esportivo em destaque.

\section{CONSIDERAÇÕEES FINAIS}

Nosso estudo apontou diversos canais de interlocução entre a EF e a mídia, seja com a televisão, a internet ou jornais impressos, numa perspectiva para reflexão crítica a partir de uma questão central, ou seja, a maneira como tais mídias antecipam e garantem visibilidade a determinados acontecimentos, aqui, especificamente, um megaevento esportivo, os JO/2012.

Percebemos que a mídia, de um modo geral, utiliza-se de estratégias para aproximar o público consumidor a partir de um megaevento esportivo, pois, mesmo o estado de Sergipe não tendo atletas sergipanos que participaram efetivamente dos JO/2012, utilizou-se do possível, a exemplo da mídia impressa, em que ficava em destaque a coordenadora da seleção de ginástica rítmica, Cristina Vital. O que reitera o entendimento de que a estratégia do envolvimento identitário, entre público, evento e mídia, chamada dialética global-local, configura-se, também, como uma interessante maneira da mídia atrair as atenções, mobilizando audiências e consumo de bens simbólicos.

Não muito diferente, os portais digitais, nos moldes jornalísticos do consumo da notícia, apropriaram-se de todos os artifícios para criar, recriar e transformar as informações, e assim, atingir o leitor/internauta/consumidor. Associam-se à relação global-local e criam ícones numa tentativa de futuras promessas para o esporte sergipano e mundial, a exemplo do boxe, numa forma de agendamento a longo prazo. O que difere um pouco do discurso midiático esportivo por meio de programas televisivos, nos quais ficam mais evidentes as narrativas para estimular a comunicação e chamar atenção do telespectador, e isto aparece desde noticiários às propagandas locais, no entanto, a mídia televisiva local fica refém das reportagens nacionais que são teleguiadas pela direção nacional da emissora.

Por fim, notamos que a cobertura midiática dos JO/2012 pela imprensa sergipana, nos três veículos aqui abordados, pouco causou "espanto" ao público sergipano. A forma como esses veículos de comunicação e suas estratégias de agendamento esportivo e da dialética global-local envolveu o fenômeno esportivo, seja em virtude do amadorismo das entidades jornalísticas, seja pela ausência de interesse em um evento em que não se tinha um ícone esportivo para fomentar informações e notícias (bastante comum e típico do jornalismo esportivo, que "personifica" a geração e veiculação de informações), por isso, demandaria um esforço sobrecomum tentar reter a atenção do (tel)espectador/leitor. Fato este que ratifica a posição indissociável entre esporte (e os atletas) e mídia.

Assim, compreendemos que a mídia enquanto um processo importante para a formação da opinião da sociedade, especificamente quando pensamos o contexto da Educação, e em especial na EF, bem como entre outros campos do conhecimento, precisa situar-se como objeto de análise para estabelecermos a reflexão crítica da informação, a partir dos acontecimentos e fatos, ou seja, não podemos ficar avessos à informação como se a mídia não se remetesse a mais nada senão a si mesma como simples mensagens. 


\section{REFERÊNCIAS}

BARDIN, L. Análise de conteúdo. 2 ed. Lisboa: Edições 70, 2009.

BASTOS, H. A diluição do jornalismo no ciberjornalismo. Estudos em Jornalismo e Mídia, Florianópolis, vol. 9, n.2, p.284-298, jul/dez 2012.

BETTI, M. Janela de vidro: esporte, televisão e educação física. Campinas: Papirus, 1998.

. Esporte na mídia ou esporte da mídia? Motrivivência, Florianópolis, ano XII, $\mathrm{n}^{\circ} 17$, set./2001.

BITENCOURT, F.G. Ritual olímpico e os mitos da modernidade: implicações midiáticas. In: CONGRESSO SULBRASILEIRO DE CIÊNCIAS DO ESPORTE, 2, out/2004. Anais. Criciúma: CBCE/UNESC, 2004.

BOURDIEU, P. Sobre a televisão. Rio de Janeiro: Jorge Zahar, 1997.

ECO, U. A falação esportiva. In:

Viagem na irrealidade cotidiana. Rio de Janeiro: Nova Fronteira, p.220-226, 1984.

JORGE, T.M. Mcdonaldização no jornalismo, espetacularização da notícia. Estudos em Jornalismo e Mídia, Florianópolis, ano V, n.1, p.25-35, jan./ jun 2008.

KUCINSKI, B. A nova era da comunicação: reflexões sobre a atual revolução tecnológica e seus impactos no jornalismo. Estudos em Jornalismo e Mídia, Florianópolis, vol. 9, n.1, p.4-17, jan/jun 2012.
MEZZAROBA, C.; MESSA, F.; PIRES, G. De L. Quadro teórico-conceitual de referência: megaeventos e o agendamento midiático-esportivo. In: PIRES, G. De L. (org.). O Brasil na Copa, a Copa no Brasil: registros de agendamento para 2014 na cobertura da midiática da Copa da África do Sul. Florianópolis: Tribo da Ilha, p.21-45, 2011.

QUARANTA, A.M.; MESSA, F. de C. A saga dos sergipanamericanos nas Olimpíadas de Pequim 2008. In: CONGRESSO BRASILEIRO DE CIÊNCIAS DA COMUNICAÇÃO, 32, Anais... Curitiba/PR, 4 a 7 de setembro de 2009. Disponível em: < http://www. intercom.org.br/papers/nacionais/2009/ resumos/R4-2434-1.pdf $>$. Acesso em: 10 junho 2012.

RIBEIRO, S.D. et al. Os atletas sergipanos em debate: análise da cobertura jornalística do Pan Rio/2007. In: PIRES, G. De L. (org.). "Observando" o Pan Rio/2007 na mídia. Florianópolis: Tribo da ilha, 2009. THOMPSON, J.B. A Mídia e a modernidade: uma teoria social da mídia. Petrópolis/ RJ: Vozes, 19998.

VERONESE, M.V.; GUARESCHI, P.A. Hermenêutica de Profundidade na pesquisa social. Ciências Sociais Unisinos, São Leopoldo/RS, n.42, vol.2, p.85-93, mai./ago 2006.

WOLF, M. Teorias da comunicação. Lisboa: Editorial Presença, 2001.

ZUIN, A.A.S. Sobre a atualidade do conceito de indústria cultural. Cadernos Cedes, ano XXI, n.54, p.9-18, ago./2001 
THE ROLE OF MEDIA IN SCHEDULING STRATEGIES IN SERGIPE IN THE MOBILIZATION OF THE GLOBAL-LOCAL DIALECTICS FROM A CONCRETE SITUATION: Olympics/2012

\begin{abstract}
With all the mega sporting events that are happening in Brazil (The 2007 Pan-American Games, The 2013 Confederations Cup, The 2014 World Cup and the 2016 Olympic/ Paralympic Games) it is possible to visualize a profitable and instigator moment for researches around this topic, concentrating our attention at the 2012 London Olympic Games. The exaltation of the sport phenomenon brought, in this research, the multiple sides through which the media can present itself and join itself with (regarding economy, culture, politics, education etc.). Our objective was to analyze how the media in the state of Sergipe anticipated and gave visibility to the 2012 Olympic Games, building a "sports-media scheduling" strategy, from the mobilization of the global-local dialectic. Characterized as a qualitative study, which has a descriptive-exploratory approach, this research was developed in three areas: print media, digital media and broadcast media - which have highlighted the low effectiveness of the scheduling strategy and the global-local dialectic strategy, whether because of amateurism in journalistic entities, or because of lack of interest, since there were no athletes from Sergipe in the competition.
\end{abstract}

Keywords: Sports-media scheduling; Olympics 2012; Sports Media

\title{
EL PAPEL DE LOS MEDIOS DE COMUNICACIÓN SERGIPANOS EN LAS ESTRATEGIAS DE PROGRAMACIÓN EN LA MOVILIZACIÓN DE LA DIALÉCTICA GLOBAL-LOCAL EN UNA SITUACIÓN CONCRETA: las Olimpiadas 2012
}

\section{RESUMEN}

Los grandes eventos deportivos que se están desarrollando en Brasil (Juegos Pan-americanos 2007; Copa de las Confederaciones 2013; Copa del Mundo 2014 y Olimpiadas y Paralimpiadas 2016), nos permiten vislumbrar un periodo propicio e instigador de investigaciones en torno a este tema, centrando nuestra mirada en las Olimpiadas de Londres 2012. La exaltación del fenómeno deportivo hizo visible, en esta investigación, las diversas caras que los medios de comunicación pueden presentar y relacionar (respecto a la economía, la cultura, la política, la educación etc.). Nuestro objetivo fue analizar cómo los medios de comunicación del estado de Sergipe anticiparon y dieron visibilidad a las Olimpiadas 2012, construyendo una "programación mediáticadeportiva", a partir de la estrategia de la movilización de la dialéctica global-local. Con un carácter cualitativo y descriptivo-exploratorio, la investigación se desarrolló en torno a tres ejes: medios de comunicación impresos, digitales y televisivos - que permitieron evidenciar la escasa efectividad de la estrategia de programación y de dialéctica 
global-local, ya sea debido al amateurismo de las entidades periodísticas, o principalmente por la ausencia de interés, pues no había atletas sergipanos en la competición.

Palabras clave: Programación mediático-deportiva; Olimpiadas/2012; Medios de Comunicación Deportiva

Recebido em: novembro/2014 Aprovado em: março/2015 